\title{
Tibetan Buddhism and the formation of ecological consciousness: a view from Buryatia
}

\author{
$K$. Bagaeva ${ }^{1, *}, D$. Tsyrendorzhieva ${ }^{1}, O$. Balchindorzhieva $^{1}$, and $M$. Badmaeva ${ }^{1}$. \\ ${ }^{1}$ Buryat State University, 670000, 24a Smolin str., Ulan-Ude, Russia
}

\begin{abstract}
Technicization of human and society, active development of technogenic civilization leads to gradual separation from moral values and principles. These values include ideas of unity and harmony of human with nature, with the surrounding environment, and reasonable, moderate attitude towards natural resources. We believe that humanity should move from the industrial to ecological civilization. The foundations of a new ecophilosophy should become holistic principles, representations of philosophy in general and Buddhism in particular. We outlined basic principles and methods for improving personality of altruistic ethics of Mahayana Buddhism that contribute to human understanding of inseparability, interconnection with the world. We focus on the central Buddhist concept - the absence of an individual ' $I$ ' that is understood as necessity of recognizing oneself as a separate empirical individual. That is confirmed by a translation of the text PrajnaParamitaHridaya Sutra from Tibetan language. The paper analyzes three types of spiritual personality that correspond to three stages of the Path to awakening. Each stage is a step towards the formation of subjectless consciousness, that is, awareness of universal dependence and responsibility for their actions. The paper argues that for ecological consciousness it is important to form an understanding that the main reason for human existence in not the technosphere, not the economy, but the living nature.
\end{abstract}

\section{Introduction}

The paper proposes to consider principles of formation of ecological consciousness on the basis of Buddhist philosophy. In Tibetan Buddhism, one of the central concepts is an idea of absence of an individual 'I'. Based on this philosophy, a person understands their inseparability, interconnection with the environment. The paper studies this relationship. The results demonstrate positive direction of human consciousness towards preserving itself as part of the whole, the nature. Interpretation of oneself as a stream of dharmas within the world's universal integrity forms a natural ecological consciousness.

Nowadays, we are witnessing how the environment's deteriorating state leads to that that the world's community begins to realize how destructive human activity was to the nature. Recently, a lot of literature, for instance [1], has appeared on the change in the consumer attitude towards the environment. However, there are no cardinal changes to be observed. Moreover, some scholars like V. I. Vernadsky [2], N. I. Lapin [3], V. V.

\footnotetext{
* Corresponding author: ksyusha.81@ mail.ru
} 
Mantatov [4], and E. A. Torchinov [5] are sure that without changing people's world outlook this problem cannot be solved.

It is probable that the ecological crisis is connected with the society's change in the value scale. The moral ideas of Christianity and Islam contribute to the human alienation from nature, conflicts and wars, technological growth. The Eastern religious cultures like Hinduism, Buddhism, Taoism, and Confucianism, on the contrary, contribute to the search of harmony with nature. The Eastern civilization is based on the traditional type of culture that involves agrarian production, extensive land development, prevalence of traditions, respect and veneration of elders, and unity with nature. The Eastern culture is introverted. It is directed into itself, self-knowledge, change of own 'I', not of an object, of nature. Therefore, the personality type that was formed in the East implied harmonious relationship with nature. This is demonstrated by such concepts as 'ahisma', which is the principle of non-violence that emerged in Vedic philosophy and exists in Buddhism.

\section{Research Methods}

Despite a large number of studies devoted to Buddhist philosophy, meditation and practice published over the past to decades (i.e. K. M. Gerasimova [6], E. A. Ostrovskaya Jr. [7]), the study of ecological problems through the prism of Buddhism is still at an early stage.

In the following sections, we will attempt to solve that problem on the basis of the methodology of hermeneutics that was developed by Western European philosophers H. G. Gadamer [8] and M. Heidegger [9]. Starting from Heidegger's formulation of the question on understanding of text, Gadamer argues that 'understanding and interpretation are related in a specific way to linguistic tradition. But they rise above this correlation not only because all, including non-linguistic creations of human culture want to be understood in a same way as linguistic ones, but - which is principally more important - also because everything that is understandable by nature should be available for understanding and interpretation' [8]. This method was originally used for interpretation of biblical and liturgical texts. In the context of this study, the paper draw shermeneutics for interpretation of Tibetan religious texts. Hermeneutics as methodology suggests studying texts as part of culture, researcher's felling of specific sociocultural environment, and appeal to context. The paper was guided by the methodology of well-known Buddhist researchers, namely by F.I. Scsherbatskoy [10], O. O. Rozenberg [11], V. I. Rudoi [12], who translated and interpreted Sanskrit texts. We translated Tibetan texts, in particular PrajnaParamitaHridaya Sutra [13, p. 113] that emphasizes the idea of absence of individual 'I'. Employing hermeneutic method allowed to isolate the text's relevant meaning. We concluded that sutra contains information on the formation of ecological consciousness. It should be noted that in the Buddhist tradition there were the so-called 'comments' on the main texts that included understanding and interpretation of the views of a particular philosophical school.

In Buddhist texts, there is no direct appeal to the problems of ecology. We may find separate expressions that form a certain field of meanings. Thus, we aim to contribute to the development of new ecological consciousness on the basis of Buddhist worldview.

\section{Results and Discussion}

The holistic approach that underlines the Buddhist ethics is characteristic for many other directions in Eastern philosophy. There was an idea of unity of Heaven and Human, macro- and microcosmin Chinese philosophy, in Neo-Taoism as far back as the 2nd century AD. The further development of such ideas in Neo-Confucianism led to an understanding of the 'one-body' nature of human with everything that surrounds them, with stone, tiles, 
birds, animals, trees, Heaven and earth. The awareness of 'one-body' is achieved through the development of person's humanity, spirituality. Using the words of Wang Yang Ming, 'the brightening of light grace' [14] that, above all, means the establishment of perfect good, rejection of selfish aspirations, sincerity, correction of the heart. 'Therefore, the desire to improve one's personality, of course, presupposes preliminary correction of one's heart. But after all, first-body of the heart is natural. Nature cannot be unkind. Consequently, first-body of the heart cannot be fundamentally wrong. Why then try to correct it? In spite of the fact that first-body of the heart cannot be fundamentally wrong, the wrong appears from the moment of the emergence and coming into motion of thoughts and aspirations. Therefore, one who wants to correct own heart has to correct what arises in their thoughts and aspirations. The appearance of a single good intention should be always met with love, truly like 'a love to charming beauty', and a single evil thought should be met with hatred undistinguishable from that 'hate to disgusting stink', then there will be no insincerity in thought and the heart could be correct' [14].

Eastern philosophy emphasizes that human is not only a part of the whole, but it is one whole that is connected by inseparable and interdependent relations.

Buddhist philosophy considers nature as not an object of subjugation, but as equal to human. The principle of independent existence is that all beings have an opportunity to reborn and become Buddha. In addition, there is a particle, kernel of Buddha, the so-called 'alaya-vijnana', which exists in every living being. Here, it is meant as the inner potential of each, by which every being is given at birth, the so-called 'Seed of Buddha'. Therefore, if there is a particle of Buddha in all beings, everywhere, then human should treat nature with special reverence. The main principle in the Buddhist philosophy is the idea of interdependence of subject and object, human and nature.

The picture of the world created on the basis of Buddhist dogma serves as a means of human integration with nature, promotes harmonious relations between people, and between different spheres of culture. This picture of the world reveals a global image of the all world that is formed on the basis and within the boundaries of certain consciousness and is conditioned by the requirements of real life. The Buddhist picture of the world is plastic and diverse [13]. "Buddhism has a reputation for being a peaceful religion that emphasizes kindness to animals and vegetarianism" [15].

The space of ecological ethics is an intellectual tradition of relations between people. Morals give human existence an inherently valuable meaning. They are also responsible for the fact of existence as human being. The ethical problem is, first of all, a problem of determining human's place in the universe. 'In the center of the Buddhist space is an ethically intelligent person. A buddhist emphasizes the special role of mind in the evolutionary process' [4].

Buddhism aims to solve intrapersonal and interpersonal conflicts through internal selfimprovement of the individual, contributing to active spiritual activity during earthly life without changing the surrounding world. Buddhist ethics is closely related to environmental issues, because karma determines human birth in favorable environmental conditions.

The law of karma is a tool of moral self-regulation that can be compared to the categorical imperative of I. Kant, which means that one should not treat other as one would not want to be treated oneself. The concept of karma is one of the aspects of teachings and chain of cause-dependent origin (pratityasamautpappa) that consists of twelve links (nidan) located in a strictly defined order. This ethical imperative is practically manifested in one of the most important Buddhist laws - the law of karma.

I. Past life (antrabhava - more precisely, a gap between death and new birth):

1. Avidya (ignorance) - lack of proper understanding of one's own nature and nature of existence, the Four Noble Truths. 
2. Ignorance leads to the appearance of samskaras (shaping factors, motivations, basic subconscious drives and impulses) that lead the deceased to a new experience of being, new birth. Intermediate existence ends and conception of new life takes place.

II. Present life:

3. Actions of samskaras lead to that the consciousness (vijnana) acquires a new birth, though not enough formed.

4. Consciousness' functioning causes the emergence of name and form (nama-rupa), that is, physical characteristics of human being.

5. On the basis of these psychological structures, six bases (shad ayatana) are formed, that is, six organs, or abilities (indriyas), sensory perceptions. The sixth indriya is manas (mind), which is also considered as the organ of perception of the 'intelligeble'.

6. Contact (sparsa) with objects of sense perception.

7. Feeling (vedana) of pleasant, unpleasant, neutral.

8. Attraction, passion (trishna) are caused by evaluative reaction: either to strive for it, or try to avoid.

9. Upadan (grasping, attachment) - human's conscious action.

10. Life, samsaric being (bhava) that ends and with the presence of karma inevitably leads to the emergence of next life.

III. Next life:

11. New birth (jati) that in turn will certainly end.

12. Death (jala-marana).

This is a content of the twelve-link chain of dependent origin, significance of which is a strict determinism of all moments and stages of human's life cycle.

The twelve-link chain of interdependent origin is closely related to the concept of karma in the sense that it is a casualty scheme with a certain mechanism of action that entails a certain result. In essence, existence of not only human, but of any living being is a result of their subsequent existence. There is nothing accidental in this world, every action has an impact, every person has a choice how to act. Therefore, each person is responsible for the future.

The literal meaning of the word 'karma' is an action. In fact, karma and its result is a description expression of existence of elements' arrangement at a certain moment in the complex plexus of their connections. And the arrangement at each moment is determent by the preceding moment. If transfer that to the living being's individual continuum, then any experience or something experienced, conceived or felt by the living being is the result of their individual karma, the essence of the totality of deeds committed by them. According to Buddha's first noble truth, it is possible to state that 'any result in the form of suffering in three kinds'. What is experienced suffering? By its very nature, the subtlest aspect of consciousness (called 'clear light') has no barriers, obstacles, difficulties, and sufferings. Its aspects of awareness and action are inseparable, that is, the property of variability is absent. Under the influence of primordial ignorance (avidy $\bar{a}$; unconsciousness, separation into internal and external), the 'inner' mind interacts with what it perceives as 'external'. The aspect of awareness is seen as 'inner essence', the subject. And the aspect of action is seen as 'external essence'. In the presence of such a division, the direction of external entity 'from inside outward' becomes action of the mind. And the direction of 'from outside inward' is an underexposed effect. This very state of susceptibility of inner ignorance contradicts with the aspect of awareness and naturally turns it into the aspect of action. That brings the mind into a state of some formation, the essence of which is in imposition by the aspect of awareness of misconception of ' $I$ ' on the aspect of action. In this way, the acting subject is constantly forced to undergo various influences, which are results of subject's 
own constantly changing actions, constantly returning to subject, since the only possible object of action is the same mind.

Essentially, a human is not put in opposition to nature and should not overpower it (as is in the Western understanding), but is only part of the community of living beings that are affected by karma. A human differs from others only by the possibility and ability to become enlightened. Since all living beings fall under the influence of karma, ethical norms are prescribed for all. Therefore, in Buddhism, a human must observe ethical rules, violation of which may lead to an unfavorable future rebirth.

In addition, this principle of interdependence shows how all living beings on the Earth are connected to each other. That causing damage to nature will also have negative impact on human.

The main thing in the formation of ecological consciousness with the help of Buddhist philosophy is to understand how a human interacts with their environment. That, first of all, is connected with the awareness of oneself as a person. In the Western European understanding, a person (personality) is formed through education, socialization. It is a socially active, responsible, and civic oriented person. In the Buddhist philosophy, a person is viewed from the soteriological point of view.

An analysis of the Tibetan sources demonstrates that the surrounding world and the person present certain strict structured dynamic integrity, called a stream (santana), that, in turn, consists of three functional groups such as 'skandha', 'ayatana', and 'dhatu'. Groups of five elements, or 'skandhas' are the following:

1. Groups of sensual (rupa) is everything that relates to the field of sensible and material

2. Group of sensuality (vedana) is a sensation of pleasant, unpleasant, or neutral

3. Group of awareness of differences, i.e. round-square, black-white, and of formation of representation and concepts (samjna)

4. Group of motivating and shaping factors - agitation and impulses (samskara)

5. Consciousness as such (vijnana)

There are ten sources of consciousness (ayatana) that represent five senses (indriya) visual, auditory, olfactory, tasting, tactile - and five sensory products - visible, audible, sensible, palatable, and tangible. Besides this, there are ten classes of elements (dhatu) in the personality structure. These are five senses - sight, hearing, smell, taste, and touch and five classes of objects - color and form, sound, smell, taste, and touch (on which aforementioned senses are directed directly). All these elements are interconnected. One of the most important aspect of consciousness in the Buddhist tradition is the concept of 'alaya-vijnana' that could be correlated with the 'archetype' of C. G. Jung. Such parallel is possible because the imprints of past lives are collected and accumulated in 'alaya-vijnana', which help to adapt to the external world in a special way. And in that human ' $I$ ' is actualized and finds its reasons.

The world's dynamic psychophysical integrity or the stream of dharmas flow, interact, and create all sorts of combinations that are stored as a label in in the 'alaya-vijnana' in form of memories. And this stream that has its basis of common memories begins to perceive itself as a single whole. That entails a delusion about the presence of eternal substance within the stream in form of so-called human soul. At this moment, the person opposes him/herself to the world. There are desires, wills, and attachments so destructive to the person. The main mental factor that forms the person's negative state is ignorance (avidya). Its presence means the presence in insamsara and absence in nirvana. According to the Tibetan Mahayana tradition, all elements do not have their own essence, but, in fact, are only names. According to some researchers, "The classical antecedent of such an ecological self is not the Hindu Âtman/Brahman - the universal substance..., but the Buddhist Anātman or Anattā (No-self)/Śūnyatā (Emptiness)" [16]. 
All constituent elements are interdependent. Everything is a cause of one, and, vise versa, one is a cause of other. It seems that if constituent elements of personality are empty (shunyata), the personality as such exists but not absolutely. 'I' exists but has a dependent existence. The main idea that ' $I$ ' does not have independent existence is that 'I' does not have such a notion as a single number. In 'I', there are no concepts of singular number 'I' and plural number 'I'. It is said in PrajnaParamitaHridaya Sutra, Shariputra, sons and daughters from Buddhist families who want to master a profound perfection of wisdom should consider five skandhas correctly and also know the essence of emptiness. A form is empty, emptiness is a form. There is no other emptiness but a form. There is no other form but emptiness. According to this, sensations, discernments, motions, consciousness are empty [13]. As pointed out by Zack Walsh, "First, meditation leads to a quieting of the narrative self. Second, this quieting of the narrative self seems to lead to at least momentary increases in well-being" [17].

Here, the subjectivism of Buddhist tradition comes to the forefront. It claims that everything is illusory and is a product of consciousness. There is only person's representation of oneself and the surrounding world. With the help of this, Buddhist theorist push the person to understand that in principle, the whole world and, naturally, the person are 'dissolved' in the absolute, in Buddha. True reality exists behind these illusory essences. Buddha is present in everyone and everything. And his essence is emptiness (shunyata). Denial of the person of things does not mean their complete non-existence. But it means the absence of an independent entity in the world permeated with interdependence and causation. The person will be happy only when they realize that they are inseparable from the absolute. And to understand the relativity of 'I' and to see own true nature is a task of the path of enlightenment.

One of the important aspects on the path of enlightenment in the Tibetan Buddhism is analytical meditative mastering when the practitioner is aware of the object being mastered, when, in essence, the ecological consciousness is being formed. On the way to it, it is necessary to go through three stages that correspond to three types of personality. Those are small, medium, and higher that were described in detail in the work 'Lam Rim Chenpo' by the Tibetan philosopher Zhe Zhouhava [18]. The person's belonging to one or another level is determined by sufficient mastery of the doctrine. The idea is that the practitioner should learn the person's strategic task at that stage and the system of values corresponding to that stage. Regarding ecological consciousness at the first stage, the person should come to understanding of what needs to be changed in oneself. And should begin to realize that everything in the world is interconnected, that a human is part of the surrounding world, inseparable part of nature. The medium personality type is the stage of a saint, when all negative factors that prevent enlightenment are revealed. The higher type of personality means awareness of oneself as bodhisattva, when the line between subjective and objective is erased. Bodhisattva practices present the following of six paramits: giving, morality, patience, determination, contemplation, and wisdom. Thus, a 'mindset aimed at the benefit of all living beings' [7] is generated, the ecological consciousness is formed.

In the Tibetan Buddhism, the notion of human essence originates from the Indian doctrine of 'anatmavada' (the absence of individual 'I'). That was later adopted by the Indian school of Buddhism called Madhyamaka that had an important impact on the formation and development of Buddhist views on human nature in Tibet, Mongolia, and Buryatia. In the Tibetan tradition, the individual 'I' is denied as an entity, as a soul. The human him/herself is the five elements (skandh) that form the human ability of learning of the surrounding world. In the Gelugpa philosophical tradition, these skandhas are considered initially 'empty', that is, lacking their own individual essence. Negative in this case is not the element and its totality as such, but its name. The initial premise of such a vision is recognition of the existence of sensory objects only in the individual 
consciousness. They are invalid because they do not have a real essence, and there is only noumena. This concept of emptiness was, first of all, a practical-active character used by the person in meditative practices to achieve an ideal human condition [13].

\section{Conclusion}

Such an ontological approach to Buddhism contributes to the formation of an open personality that, in our opinion, helps Buddhism to adapt in any historical and sociocultural conditions. In this aspect, that is applicable to the creation of special ecological consciousness. It should be noted that Buddhism imbibed itself and elements of autonomous beliefs of those peoples on whose territory it was spreading. A vivid example is Central Asia, Mongolia, and Buryatia. These regions clearly demonstrate assimilation of the Buddhist ecological traditions of the Buryats and Mongols.

The animistic worldview of Mongols and Buryats, which manifested in sacralization of places of nature, was reflected in the Buddhist worldview. Local gods became Buddhist defenders. Lakes, rivers, ponds, and mountains, especially revered in Shamanism, also became sacred in Buddhism. For the nomads, the balance with nature was very important. It is forbidden to kill more animals than needed, cut down forests, pollute water bodies. The Buddhist worldview supplemented these views with a deeper philosophical meaning.

Thus, the Buddhist philosophy has experience and ways of solving environmental problem. After all, Buddhist ethics is based on love and respect for everything around us.

Therefore, the formation of ecological consciousness is connected with a turn to moral and spiritual values, behavior rules aimed at achieving harmony between human and nature, society, and environment. Transition to ecological consciousness, in our view, should become an irreversible global trend. Fundamental values of that are developed in the process of persistent theoretical and practical work. To really succeed in developing ecological consciousness, the society will have to go in an even more radical direction moving away from 'excessive consumption' and approaching foundations of 'spiritual personality'. There is reason to believe that ideas of Eastern philosophy, in particular Tibetan Buddhism, will contribute to the society's move towards ecological consciousness.

\section{References}

1. B. C. Budaeva, Ethnoecological traditions: history and sovremennosti (Publishing house of ESSUTM, Ulan-Ude, 2003)

2. V. I. Vernadsky, Selected works on the history of science (Moscow, 1981)

3. N. I. Lapin, Problems of Philosophy, 4 (2015)

4. V. V. Mantatov, Ecological ethics of Buddhism (Buddhist culture: materials of the international symposium) (Publishing house of Zabgpu, Chita, 2001)

5. E. A. Torchinov, The interaction of buddhist and traditional Chinese beliefs about the world (Andreev and Sons, St. Petersburg, 1993)

6. K. M. Gerasimova, Renovationist movement of the Lamaist clergy (Ulan-Ude, 1964)

7. Jr. E. Ostrovskaya, A tibetan buddhism (Saint Petersburg, 2002)

8. H. G. Gadamer, Truth and method: foundations of philosophical hermeneutics (Progress, Moscow, 1998)

9. M. Heidegger, Time and being: the art and performances (Respublika, Moscow, 1993)

10. F. I. Shcherbatskoy, Selected works on Buddhism (Nauka, Moscow, 1988) 
11. O. O. Rozenberg, Works on Buddhism (Nauka, Moscow, 1991)

12. V. I. Rudoi, E. P. Ostrovskaya, About the specifics of the historical and philosophical approach to the study of Indian classical religious and philosophical systems (Nauka, Moscow, 1987)

13. K. A. Bagaeva, The Ideological foundations of the Gelugpa tradition in Central Asia (Publishing house of the Buryat State University, Ulan-Ude, 2012)

14. A. I. Kobzev, Philosophy of Chinese neo-Confucianism (Moscow, 2002)

15. D. Finnigan, Philosophy Compass, 12, 7 (2017)

16. P. Verhaeghen, Contemporary Buddhism: An Interdisciplinary Journal, 8, 1 (2017)

17. Z. Walsh, Religious Studies Review, 43, 2 (2017)

18. Je. Tsongkhapa, A Great guide to the stages of the Path of Awakening (St. Petersburg, 1994). 